\title{
Can biochemical markers be used to predict the rate of achieving tight glycaemic control in critically ill adults?
}

\author{
P. Turner ${ }^{1}$, A. Sanusi ${ }^{2}$, B. Perry ${ }^{3}$, A. Shenkin ${ }^{3}$ and I. Welters ${ }^{4}$ \\ ${ }^{1}$ Department of Nutrition and Dietetics, Royal Liverpool University Hospital, Liverpool L7 8XP, ${ }^{2}$ University of Ibadan, \\ Anaesthesia/Critical Care, Nigeria, ${ }^{3}$ Department of Clinical Chemistry, Royal Liverpool University Hospital and \\ ${ }^{4}$ Department of Anaesthesia, University of Liverpool L69 3GA
}

Critically ill patients often become hyperglycaemic due to insulin resistance and increased gluconeogenesis that occurs as part of the inflammatory response. There is strong evidence that controlling this hyperglycaemia with intensive insulin therapy to maintain blood glucose levels between 3 and $6 \mathrm{mmol} / \mathrm{l}$ reduces morbidity and mortality ${ }^{(1)}$. It may be useful to identify the patients in which tight glycaemic control is likely to be difficult to achieve so that they can be closely monitored, their energy and carbohydrate provision optimised and overfeeding avoided.

A study of all consecutive admissions to a mixed surgical and medical intensive care unit (ICU) over an 8-week period was undertaken to see if biochemical indices of inflammation correlated with mean insulin dose and time to achieve glycaemic control defined as two blood glucose readings between 4 and $8 \mathrm{mmol} / \mathrm{l}$. Patients were included in the study if they received artificial nutritional support for more than $48 \mathrm{~h}$. Twenty-two males and eighteen females were recruited, with $62.5 \%$ receiving enteral feeding, $7.5 \%$ parenteral and the remainder both. Biochemical parameters measured within $24 \mathrm{~h}$ of admission to the ICU (see Table) were C-reactive protein (CRP) as a marker of inflammation, $\mathrm{Zn}$, Se and prealbumin as negative acute phase reactants and $\mathrm{Cu}$ as a positive acute phase reactant. BMI, total energy and energy from carbohydrate were also recorded as these may affect glycaemic control.

\begin{tabular}{lccr}
\hline Reason for Admission to ICU & Males & Females & Total \\
\hline Respiratory failure (RF) & 11 & 8 & 19 \\
Surgery & 5 & 8 & 13 \\
Trauma + RF & 0 & 1 & 1 \\
Pancreatitis & 4 & - & 4 \\
Surgery + RF & - & 1 & 1 \\
Others & 2 & - & 2 \\
Total & 22 & 18 & 40 \\
\hline
\end{tabular}

The mean BMI was $28 \mathrm{~kg} / \mathrm{m}^{2}$. There was no correlation between time to achieve glycaemic control and CRP $(r 0.06), \mathrm{Zn}(r-0.34)$, Se $(r-0.06)$, prealbumin $(r$ 0.28), $\mathrm{Cu}(r-0.07)$, BMI $(r-0.13)$, total energy intake $(r$ 0.29) and energy from carbohydrate $(r$ 0.27). Similarly there was no correlation between total insulin dose to achieve glycaemic control and CRP $(r-0.069)$, Zn $(r$ 0.190), Se ( $r$ 0.096), prealbumin $(r-0.179), \mathrm{Cu}(r$ 0.28), BMI $(r-0.129)$, total energy intake $(r 0.351)$ and energy from carbohydrate $(r 0.118)$.

This small study would suggest that it is not possible to predict the rate of achieving tight glycaemic control using biochemical markers or BMI.

1. Van den Burghe G, Wouters P, Weekers F, Verwaest C, Bruyninckx D, Schetz M, Vlasselaers D, Ferdinande P, Lauwers P \& Bouillon R (2001) New Engl J Med 345 (19), 1359-1367. 